\title{
Giving Voice to Consciousness
}

\author{
Neuroethics, Human Rights, and the Indispensability \\ of Neuroscience
}

\section{JOSEPH J. FINS}

\begin{abstract}
In the 2015 David Kopf Lecture on Neuroethics of the Society for Neuroscience, Dr. Joseph Fins presents his work on neuroethics and disorders of consciousness through the experience of Maggie and Nancy Worthen, a young woman who sustained a severe brain injury and her mother who cared for her. The central protagonists in his book, Rights Come to Mind: Brain Injury, Ethics and the Struggle for Consciousness (Cambridge University Press, 2015), their experience is emblematic of the challenges faced by families touched by severe brain injury and the possibility for improved diagnosis and treatment offered by progress in neuroscience. By telling their story, and those of other families interviewed as part of the research for Rights Come to Mind, Fins calls for improved care for this population arguing that this is both an access to care issue and a civil and disability rights issue worthy of greater societal attention.
\end{abstract}

Keywords: neuroethics; disorders of consciousness; brain injury; vegetative state; minimally conscious state; civil rights; disability rights; narrative ethics; neuroimaging; deep brain stimulation; narrative ethics

\section{Maggie and Nancy}

I want to introduce you to Maggie Worthen. I share her story with the permission of her mother, Nancy Worthen. They were both subjects in institutional review board-approved translational research conducted at Weill Cornell Medical College and Rockefeller University designed to understand mechanisms of recovery from severe brain injury and barriers to care for these patients and families. As part of that research I conducted in-depth interviews with more than 50 families touched by severe brain injury. I am grateful for their participation and have their consent to mention them by name. ${ }^{1}$

When Maggie was a student at Smith College she had a brain stem stroke that extended up into her thalamus. It happened during Senior Week, after she had completed all her finals. She graduated with her class in absentia, as she was critically ill, still in intensive care. Her classmates marched in commencement wearing little blue ribbons to stand in solidarity with their fallen friend.

A video clip shows Maggie using a brain-computer interface that tracks her eye movements. ${ }^{2}$ In it, bedecked in a neuroprosthesis, she is moving her left eye intentionally downward in response to questions. With the help of technology, she is

Editor's note: “Giving Voice to Consciousness: Neuroethics, Human Rights, and the Indispensability of Neuroscience" was delivered as the 2015 Society for Neuroscience David Kopf Lecture on Neuroethics.

Acknowledgements: The author is grateful to the Society for Neuroscience and Kopf Industries for the opportunity to present the 2015 David Kopf Lecture on Neuroethics and for the ongoing support of the Jerold B. Katz Foundation. He also greatly appreciates the editorial support of Jennifer Hersh. 
communicating, no small task for a young woman who was thought to have been permanently unconscious and in a vegetative state.

If one picture, or video, is worth the next thousand words I will share with you, that brief clip captures my morning's theme: how neuroscience and neurotechnology can help a person otherwise sequestered from human community to communicate and engage with the outside world. ${ }^{3}$ It reveals what we might do and is aspirational as well: it illustrates why it morally matters to advance and sustain this work. That is, it illustrates how patients like Maggie, considered to be in a minimally conscious state, can overcome what has been described as a cognitive motor dissociation in which motor output is unable to reflect what might be going on in their head. ${ }^{4}$ More simply put, it shows how we can help Maggie-and those like her-get outside her head and tell us she is there, communicate whether she is in pain and needs help, and even tell the people who love her that she knows who they are and that, yes, she loves them too.

Those downward eye flicks don't look like much, but to get Maggie to that point was a Homeric odyssey that overcame social stigma and an indifferent healthcare system ${ }^{5,6}$ and drew on some of the most exciting developments in systems neuroscience. ${ }^{7}$ She couldn't have done it without the help of neuroscience.

Maggie's story is worth telling because, sadly, it is seldom reproduced, and patients like Maggie who are minimally conscious are routinely misdiagnosed

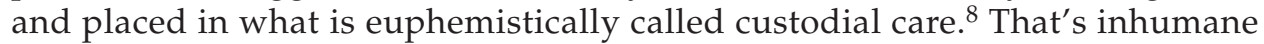
and unjust and a national scandal that we need to correct. We can, and must, do better, and neuroscience is beginning to provide the tools we need to make this possible.

The question is, will this fledgling area of neuroscience be sustained? And if it realizes its full potential, will society be ready for its consequences and its potential to reshape what we owe people on the edge of consciousness?

I have faith in my scientific colleagues and what they might achieve, but I am less certain that society will embrace the civil rights of these individuals. ${ }^{9,10}$ That struggle needs to begin now, as this science progresses, lest we lose the opportunity to make a real difference in the lives of patients and families touched by severe brain injury. To start that journey, though, we need to understand why society has come to neglect patients with severe brain injury.

\section{Brain Injury and the Right to Die}

This issue is a tangled story at the core of the emergence of modern American bioethics, which has been predicated on the centrality of patient self-determination and choice. ${ }^{11}$ Those choices took root in issues related to reproductive choice and decisions about how we die, ensconced in two landmark cases: Roe v. Wade in 1973 and the Karen Ann Quinlan case in 1976, which centered on the right of Julia and Joe Quinlan to remove life-sustaining therapy from their daughter, who was in a persistent vegetative state. ${ }^{12}$

The persistent vegetative state was first described in $1972^{13}$ by Bryan Jennett, the Scottish neurosurgeon also known for the Glasgow scales, ${ }^{14}$ and Fred Plum, the North American neurologist also known for describing the locked-in state. ${ }^{15}$ Fred was my teacher, and later a colleague.

Jennett and Plum described the vegetative state as a state of wakeful unresponsiveness in which the eyes are open but there is no awareness of self, the environment, 
or others. ${ }^{16,17}$ Vegetative patients exhibit nonpurposeful behaviors such as sleep/ wake cycles, blinking, eye movements, and even the startle reflex, but they are neither conscious nor self-aware. Despite their confounding eyes-open state, they are neither cognizant of others nor aware their environs. Their functions result from autonomic brain stem function.

The vegetative state was central to the evolution of the right to die and was a pillar of American bioethics, which was predicated on an evolution of the concepts of self-determination and autonomy in which the right to die evolved as a negative right to be left alone. ${ }^{18}$ The withdrawal of care was justified in these futile cases based on the loss of one's cognitive, sapient state.

This logic was at the core of Judge Hughes's decision to permit the removal of Ms. Quinlan's ventilator. He cites the testimony of Dr. Plum, the court-appointed physician, as he distinguishes the ethical and legal significance of differential levels of brain function:

It was indicated by Dr. Plum that the brain works in essentially two ways, the vegetative and the sapient. ... We have no hesitancy in deciding ... that no external compelling interest of the State should compel Karen to endure the unendurable, only to vegetate a few more measurable months with no realistic possibility of returning to any semblance of cognitive or sapient life. ${ }^{19}$

Although there is an inherent paradox in that argument-in that it asserts that the vegetative state is neither cognitive nor sapient and yet is still unendurable- the decision was of significant importance. It established a right to die, launching a movement that has continued to this today. For our purposes, it is critical to note that the right to die was birthed in the context of severe brain injury and that association has lingered and deepened. ${ }^{20,21}$

Over the ensuing years since Quinlan in 1976, North American physicians became acculturated to a right to die. ${ }^{22}$ The vegetative state became the ultimate in medical futility. Nothing can or should be done for these patients. The image was of the vegetative brain described in the New England Journal of Medicine autopsy report of Quinlan: a brain that was a gelatinous gel, half the weight of a healthy brain..$^{23}$ This was not the substrate for cognition, sapience, or recovery.

Since Quinlan, the vegetative state has been at the epicenter of the right to die. ${ }^{24}$ It first appeared in the 1990 landmark Cruzan case, in which the U.S. Supreme Court held that competent adult patients could refuse life-sustaining therapy and that states could establish evidentiary standards to determine an incapacitated patient's prior wishes. ${ }^{25}$ Justice O'Connor's opinion also inspired Senators Danforth and Moynihan to draft federal legislation about advance directives, ${ }^{26}$ the Patient Self-Determination Act, ${ }^{27}$ further linking the vegetative state to the right to die. And then in the contentious dispute over Terri Schiavo, ${ }^{28,29,30,31,32}$ the fate of the right-to-die movement hinged on the accuracy of that woman's diagnosis, further associating the vegetative state with questions of life and death. A cover from U.S. News and World Report attests to the association, asking prominently what Schiavo means for "life, death and politics." 33,34

But this was only part of the story. As important as the futility of the permanent vegetative state was to the establishment, and sustainability, of the right to die, it became increasingly clear that the futility of the vegetative state was overgeneralized 
to other patients with severe brain injury. This development was, in part, responsible for a pervasive medical nihilism toward these patients. ${ }^{35}$ This became especially worrisome when a new group of patients began to emerge who resembled vegetative patients but did not quite follow their trajectory. ${ }^{36}$ Nestled within the vegetative state was a subset of patients who had a condition that did not yet have a name. ${ }^{37}$

At the bedside, these patients appeared vegetative, but they were not. Some of these patients got better and regained consciousness, sometimes years and decades after being in what was thought to be a vegetative state. As we came to realize, these patients, like Maggie Worthen, were in a minimally conscious state.

The minimally conscious state (MCS) was first described in a 2002 paper in Neurology. ${ }^{38}$ Based on the Aspen criteria, a minimally conscious state is a state distinct from a vegetative state in which patients are conscious. Minimally conscious patients demonstrate intention, attention, and memory. They will say their name, track a person who enters the room, or grasp for a cup. The challenge is that they manifest these behaviors unreliably and episodically. If asked to repeat a behavior for a clinician called to see the patient by the family, chances are that-because of the biology of the condition-the behavior will not be repeated.

Of course, this creates a problem for families who make observations that are not reproducible. Clinicians will write such observations off as denial or wishful thinking. And of course that may be so. ${ }^{39,40}$ But there is another possibility that is wholly consistent with the circuitry of the MCS, which is intact but not always active. That the network or circuit has the potential to work distinguishes a MCS from a vegetative state, in which networks are permanently destroyed. The MCS is a condition of potentiality, with the substrate retaining both a structure and a function capable of potential activation.

\section{A Galenic View of the Injured Brain}

That we have had a hard time changing our views about the immutability of the brain should come as no surprise. This idea is not just the product of the modern era but a view that has ancient origins. Going back to Hippocrates, medicine has been rather conflicted-if not nihilistic-about severe brain injury.

But there is an alternative vision, as depicted in a ceiling panel from the Montreal Neurological Institute designed by the great neurosurgeon Wilder Penfield. ${ }^{41}$ Against the backdrop of Golgi cells is an early symbolic depiction of the brain and hieroglyphics. In Greek around the inner circle is a quote from Galen refuting a Hippocratic aphorism asserting the dire nature of brain injury. Against this claim, Galen asserts, "But I have seen the injured brain healed."42

And so have I. ${ }^{43}$

Indeed, if there were a game changer that affirmed the Galenic versus the Hippocratic school on brain injury, it would be the case of Terry Wallis in 2003. ${ }^{44}$ Then a 39-year-old, Wallis had been in a "coma" since a car accident in 1984. In July 2003, 19 years later, he had a "miracle awakening." He started to speak, saying, "Mom" and "Pepsi" and gaining greater fluency over the ensuing weeks. But he was stuck in time, much like Augustine's eternal present. For him, it was still 1984, when he had his accident. Ronald Reagan was still president of the United States. ${ }^{45}$ A modern-day Rip Van Winkle, his story gained international media coverage. ${ }^{46}$ 
Wallis had been thought to have been vegetative, but a review of the medical record revealed that, for the past 19 years, he had been not vegetative but, rather, in a minimally conscious state. ${ }^{47}$ For the first 18 years after his injury, he was in a diagnostic category that did not exist until the Aspen criteria of 2002. But a review of his history-and interviews with his family - suggests that he became minimally conscious several months after his brain injury. ${ }^{48}$

Years later, Mrs. Wallis told me a haunting story from the early 1990s, which I recount in my book, Rights Come to Mind: Brain Injury, Ethics and the Struggle for Consciousness. ${ }^{49}$ Wallis was in his bed overnight in a nursing home in Arkansas. The nurses found him in the morning upset and with his eyes wide open. Of course, vegetative patients are not supposed to emote or respond to their environment, but the nurses who saw him must not have read the medical texts. They saw he was upset and called his mother to console him.

The details of what happened are unclear, but Terry's roommate in the nursing home, an elderly patient with dementia, had evidently strangulated himself in his sheets. Terry had been aware of this, and his awareness violated the diagnosis of a vegetative state. Mrs. Wallis told me:

\begin{abstract}
One of the aides called me from work one morning and told me she was not supposed to do that but ... that man had passed away that night, and that it had bothered Terry. . . . I needed to be down there. ... [When she arrived] Terry was lying there with his eyes open wide, he would not go to sleep, I mean he was making no noise at the time. But I stayed there with him most all the day until he finally went to sleep. So I don't know what he saw, but I know he saw something. And I know it had, now, I knew then it had to be something that was really bad. ${ }^{50}$
\end{abstract}

Terry would have to wait more than a decade for a diagnosis that would accommodate his true condition. ${ }^{51} \mathrm{He}$ was minimally conscious and capable of the awareness that his mother suspected before there was a diagnostic category that would accommodate his brain state.

And as striking as that narrative is the neuroimaging of his brain. It had, as Galen suggested, begun to heal. Diffusion tensor imaging done at Weill Cornell and published in the Journal of Clinical Investigation indicates a dynamic, changing brain. ${ }^{52}$ My colleagues identified possible axonal sprouting, new axons connecting remaining neurons, and their eventual pruning, recapitulating what occurs in the developing, maturing brain. ${ }^{53,54}$

\title{
Cortical Integration and the Minimally Conscious State
}

In functional imaging, an MCS brain looks different than a permanently vegetative brain. This potentiality resides in the presence of intact neural networks and the ability of the brain to act in an integrated fashion. This contrasts with the disintegrated physiology of the vegetative state, in which brain networks are disrupted.

This distinction is seen in the work of Steven Laureys of Liege, in which he uses neuroimaging to illustrate a differential response to painful stimuli in vegetative subjects versus normal controls. In the vegetative subjects, only the primary sensory area is activated. In contrast, the entire pain network, with associated cortical areas, is activated in normal subjects. ${ }^{55}$ 
In contrast to patients in a vegetative state, MCS patients demonstrate functional integration of their brains through network activation in response to language. A landmark study done by Schiff and Hirsch in 2005 showed that MCS patients selectively activated a network response when exposed to narratives recorded by loved ones. When these narratives were played backward, with the same frequency spectrum, network activation did not occur. ${ }^{56}$

This had profound moral significance to me and was the neuroimaging correlate to what Terry Wallis experienced in that nursing home decades ago. ${ }^{57}$ It suggested, as I remarked in the New York Times, that these patients were responding to language, a finding of exceptional scientific and normative importance. ${ }^{58}$ It also showed their potential for profound isolation, because we had been treating them as if they were exiled from the human community, when in fact they were responsive to language.

The story became more complex in 2006, when Adrian Owen and colleagues published the case of a 23-year-old patient who had been determined to be in a vegetative state by behavioral criteria. However, the patient responded to active stimulation, was able to imagine walking through her house and playing tennis, and could distinguish similarly sounding words. ${ }^{59}$ In response she activated motor, spatial, and linguistic networks. In response to this discordance between the clinical exam and what was discerned through neuroimaging, I suggested with Schiff that we refer to this category as the nonbehavioral minimally conscious state. ${ }^{60}$

More recently, in 2010, Martin Monti and colleagues utilized the active stimulation paradigm developed by Owen and toggled these network responses to yes/no responses. ${ }^{61}$ In this way, a communication channel was established with a patient who until that time was thought to be vegetative. Although this patient was later determined to demonstrate behavioral evidence of consciousness when tested again with the coma recovery scale-revised (CRS-R), ${ }^{62}$ the Monti paper was remarkable on two counts: its use of neuroimaging both as a neuroprosthetic and as a diagnostic tool that identified as conscious a patient otherwise thought to be vegetative. Although the CRS-R remains more sensitive as a diagnostic tool, for the one patient who was flagged as conscious by neuroimaging, this additional diagnostic information was pivotal.

Maggie participated in an active paradigm study at Weill Cornell. Knowing that she was as swimmer, we asked her to imagine herself swimming instead of playing tennis. ${ }^{63}$ She too demonstrated a response consistent with healthy volunteers in response to command following. This neuroimaging helped Nancy convince her friends and neighbors that Maggie was there. As she put it, people "are thinking about her differently." 64

\section{Pathways and Barriers to Recovery and Care}

The challenge is that, as we come to apprehend the science of disorders of consciousness, patients face the challenge of having dynamic brain states as they traverse a rather static and unresponsive healthcare system. ${ }^{65}$

The temporal evolution of these brain states is complex, ${ }^{66}$ and this biological trajectory presents challenges when admixed with the sociology of modern healthcare ${ }^{67,68}$ In the acute care setting, patients who may have the potential for additional recovery are often subject to premature decisions to withhold or withdraw 
life-sustaining therapy before they have declared themselves prognostically. ${ }^{69}$ Families are also approached to consent for potential organ donation..$^{70,71}$

Families must navigate a maze of diagnostic terminology and prognostic uncertainty. Making choices about end-of-life care is complex because the loss of consciousness in severe brain injury is quite distinct from that associated with end-stage terminal disease. It may lead to brain death, but it also might be the first step in recovery.

Nancy recalls agreeing to a do-not-resuscitate order for Maggie but having second thoughts about the desirability of organ donation as her daughter improved. She told me:

But then there was another moment, I think I was making a different decision, maybe it was when I was going to do the rehabilitation route [when the organ transplant people returned]. They came back and the social worker kind of pulled them away like dogs, "Get away from her." It was sort of a strange moment, because I was so vulnerable that I just was like, "What are you talking about? Get away from her." . . It was difficult. ${ }^{72}$

Patients are perhaps the most vulnerable when they are not yet in a permanently vegetative state and are discharged from the hospital to lower-acuity settings where they surreptitiously move into the minimally conscious state unnoticed because the behaviors that make the distinction are episodic and not reproducible. ${ }^{73}$

Indeed, a paper by Schnakers et al. revealed that 41 percent of patients in an international cohort of brain-injured patients diagnosed as vegetative were in fact found to be minimally conscious ${ }^{74}$ when assessed using the metrics of the coma recovery scale developed by Joseph Giacino. ${ }^{75}$ This error rate, which is consistent with previous studies, is alarming and demonstrates the complexity of the state and a lack of diffusion about emerging diagnostic categories as well as a lingering nihilism when it comes to brain injury.

I want to bring to your attention another aspect of temporality about MCSs that has profound ethical implication: there is no time correlation between the probability of emergence from a MCS and the amount of time one is in that state. ${ }^{76}$

As Lammi has noted, there is a low correlation coefficient between the duration of a MCS and the outcome measure, and this suggests that prognostic statements about the length of time a person is in a MCS cannot be made with confidence. ${ }^{77}$ This creates tremendous prognostic uncertainty, as well as potentiality. This tenuous mix means that once a patient is in a MCS, he or she has an ongoing possibility of emergence. We just cannot predict if it will occur, or when it will happen.

This latency related to recovery and its time course has profound implications for families as they wait expectantly for a recovery that may or may not occur. A most moving story is that of Don Herbert, a fireman from Buffalo, New York, who was not part of our cohort but was the subject of a book by Richard Blake. ${ }^{78}$ Herbert was in a house fire on December 29, 1995, when he suffered what was thought to be anoxic brain injury but was more likely traumatic, which as we have said has a better prognosis. He was struck on the head by a roof beam after being hyperventilated by his oxygen mask. In early 1996 he had some rare speech. Then he became quiescent and seemingly vegetative for the next nine years. ${ }^{79}$ 
Then, in 2005, he regained fluent speech. Here is what I wrote about the case in a JAMA book review. ${ }^{80}$ The nurses at the nursing home where he resides are stunned and call Linda Herbert, his wife, on her cell phone. She in turn calls her teenage son and instructs him to call his father's room so as to maintain contact to keep him from slipping away again as she rushes over in her car. Imagine the pathos of the young boy told to call his father because he was talking, after all the years of silence. But Linda did not want to lose her husband again and wanted her son to keep that tenuous thread from another irreparable rupture. When Nicholas calls his father,

\begin{abstract}
Herbert is incredulous that the teenage voice is his little buddy, Nicky. "This isn't Nicholas-he's a baby, he can't talk!" Nick responds to his Dad, "I can talk. . . . Do you know how old I am?" He tells him, "I'm thirteen.' Don responds with a vernacular, "Holy ..."

The spicy response encapsulates the missed years and flashes of the fireman's personality. The conversation concludes with Don telling his son he loves him. Later, Linda asks how Don sounded. Nicky reminds her, "I don't know. I can't remember ever hearing him speak before."

For nearly 16 hours Don is back talking with friends and family.

There are echoes of Joyce's Ulysses, that literary day in Dublin which became a microcosm for an entire lifetime. Elation is mixed with Don's fatherly guilt, "I've been gone a long time ... " 81
\end{abstract}

What is truly remarkable about Herbert's reaction is that he knows who he is and feels that he failed his family. He retained a father's sense of obligation and responsibility, even though his absence was not of his own doing. He had been there, even as he was abandoned by the healthcare system and was receiving custodial care in a nursing home until an earnest physiatrist took an interest in his situation and administered a mix of agents that activated intact but until then dormant neural networks consistent with a MCS.

\title{
Rehabilitation and Access to Care
}

What is especially tragic about Don Herbert's case is that it lay unattended to for nine years, beyond the reach of rehabilitation, despite the entreaties of his wife, who wrote to medical centers all around the country asking for help. ${ }^{82}$ Her valiant quest was emblematic of the challenge that patients and families face in getting timely and competent neurorehabilitation and having it reimbursed.

Our reimbursement system, and the clinically constraining construct of "medical necessity," 83,84 is predicated on the demonstration of overt behavioral improvement and the achievement of practical results. ${ }^{85}$ Although this improvement standard was the subject of a class-action lawsuit in Jimmo v. Sebelius and led to a reform of the Medicare policy manual, local care determinations on the ground are still predicated on patients showing behavioral improvements. ${ }^{86,87,88}$ This can be an oxymoron in patients whose recovery may be happening in their heads before being manifested behaviorally.

Maggie, like pretty much all the individuals I interviewed, ran into this challenge, which compromised her care and her prospects for improvement. Nancy told me:

You know how there's those rules about you only get physical therapy if you progress from one level to another in a certain number of days. 
So obviously someone who is minimally conscious is less likely to succeed in those categories even though they might need physical therapy. Those benchmarks don't work for people who are not conscious. But they're still used. ${ }^{89}$

Put more bluntly, brains only recover slowly by reimbursement standards, not biological ones. In that context, they are just on time. We have to reset that clock ... to tap into the resilience and potentiality of patients in a MCS. ${ }^{90,91}$

\section{Toward a Therapeutics of Disorders of Consciousness}

At an exploratory meeting at the Institute of Medicine we raised these questions about the resilience of the MCS brain and potential therapeutic intervention. ${ }^{92}$ Three basic pathways have emerged to tap into the latent network-based capabilities of MCS patients: drugs like amantadine and zolpidem, which can alter brain states and/or accelerate the pace of recovery of consciousness; as we have seen, the use of neuroimaging as a neuroprosthetic communication channel; and, perhaps most dramatically, our use of deep brain stimulation (DBS).

Because I was a coinvestigator in the use of DBS in MCS, I would like to focus on our study published in Nature in 2007.93,94,95 I was responsible for designing the ethical framework, identifying the target population to achieve the proper balance of innovation and proportionality, and addressing the challenge of surrogate consent for a Phase I intervention in a patient who could not provide consent. ${ }^{96,97,98,99,100,101,102,103,104,105}$

I argued that we should not conflate the inability to obtain consent from the decisionally incapacitated with disrespect for personhood when the object of the intervention is the restoration of the very communicative ability central to the restoration of agency. ${ }^{106,107}$ I also insisted that, should a subject regain decisionmaking capacity because of our intervention, they should be reconsented to provide continued authorization for study enrollment. ${ }^{108}$ Our work was approved by multiple institutional review boards and was done under a new investigational device exemption under the U.S. Federal Food and Drug Administration. ${ }^{109,110}$

The subject of the study was a 38-year-old, right-handed man who had sustained a closed head injury following an assault six years prior to entry into study. He had sustained blunt trauma to the right frontal lobe, which produced bilateral subdural hematomas (right > left) with significant mass effect; had subfalcine and central herniation; and had an initial score of 3 on the Glasgow Coma Scale. He transitioned into a MCS, two to three months after injury and had a stable baseline since, with his highest functional level being inconsistent command following with eye movements. ${ }^{111}$ Bilateral electrodes were inserted into the intralaminar nuclei of the thalamus because of its central position: it both projects down into the brainstem, which was necessary for arousal, and has widespread projections across the cortex as the more primitive brain. ${ }^{112}$

We tracked cognitively mediated behaviors like speech, limb control, and oral feeding. With stimulation he could say 6- to 7-word sentences, recite the first 16 words of the American Pledge of Allegiance, and tell his mother he loved her. For the first time, he could eat by mouth and was not dependent on a feeding tube. He also had improved limb control. All of these developments correlated 
with stimulation. This was the first demonstration of proof of principle that DBS could promote late recovery in severe traumatic brain injury. ${ }^{113}$

Like most innovations, what we accomplished was what the late Lewis Thomas, physician and essayist, called a "half way technology" that "ameliorates but does not eliminate" a problem. ${ }^{114}$ In this case, what was achieved was mind from brain and the restoration of personal agency via a neuroprosthetic device. The restoration of agency was vividly displayed one hot summer day posttrial when we were doing stimulation parameters. The subject, now a patient, was getting tired, and one of the therapists asked him if he wanted to stop. He said yes and we did. ${ }^{115,116}$

This event almost went unnoticed until I noted that the patient was now at some level directing his care, when before he was totally reliant on surrogates. To me it was vindication of our study design, which would have required that a patient who regained capacity be reconsented for study inclusion. Although this interaction was not at the level of formal consent and refusal, because he could not initiate queries, it was at the level of assent and dissent.

That moment encapsulated what had been accomplished. Through a neuroprosthetic device, functional communication had been restored, and with communication we had restored community, placing this subject back into the nexus of relationships that had informed his life before his injury. ${ }^{117}$

\section{Crying for Cory}

Of course the work has not been without its critics, including colleagues in medical and neuroethics. The argument goes like this: we have now made a person more aware of his deficits and the horrors of his compromised existence. One commentator, Grant Gillet, in a paper provocatively entitled, "Minimally Conscious State, Deep Brain Stimulation and What Is Worse than Futility," asserts that our DBS in MCS work resulted in a "risk of unacceptable badness."118

Of course we worried about what we did. We worried a lot and took some solace in the fact that neuromodulation could be reversed. The stimulator could be turned off if need be. ${ }^{119}$ And, I must admit, I was myself frightened about the moral consequences of what we did when Corinth Pecco, the mother of Greg Pearson, the young man who was the subject in the Nature paper, told me Greg was depressed. ${ }^{120}$

With Ms. Pecco's permission, I want to share a story that has stayed with me since she related it to me, as a participant in our narrative study. When asked if this has been a "good chapter," she told me, "Yes, it has." Before the surgery, "you don't know how he feels, because in six years he didn't say a word. He never opened his mouth to say anything. ... Now to have him say words.... . These are things he couldn't do before." Her impressions are recounted in my volume Rights Come to Mind: Brain Injury, Ethics and the Struggle for Consciousness. ${ }^{121} \mathrm{Ms}$. Pecco continues:

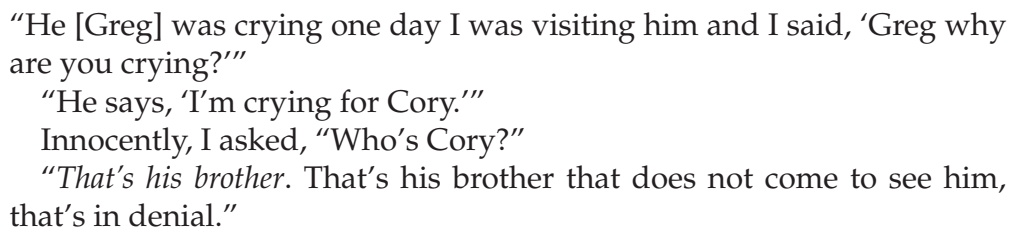


Corinth's analysis, "And even I started crying because here he is, he's aware, he knows what's going on." To the surprise of his mother, Greg remembered he had a brother and knew that he had not come around to visit. The brief comment that he is crying for Cory, suggests memory and implies that he is hurt. And perhaps even that Greg is crying because Cory is grieving for his brother. It is a comment pregnant with meaning and one that begs caution for any commentator who assumes that they know the latent content of this discourse without knowledge of its context and provenance. To engage in precipitous analysis would be to again silence patients like Greg after they had regained voice.

Corinth repeats herself, "So for him to say that day, I said, 'why are you crying?' He says, 'I'm crying for Cory.'"

Greg said it "plain" and softly and "not as loud as I'd like to hear him." Both in tone and substance, there was sadness in Greg's voice and Corinth's recounting. The repetition is to remind herself that Greg's comment suggests a level of understanding that his laconic speech does not fully convey. Here is a person embodied in that soft-spoken voice with a full repertoire of sentiments. Greg is keenly feeling the absence of a brother he still loves.

And his recollection of Cory prompts another admission, the possibility that Greg misses others too. Then, Corinth tells me, "I'm sure he misses [Cory], and he has a daughter that does not come to visit him."

By this point, I had known Corinth for a couple of years and did not know that Greg had a child. But all of a sudden, his ability to communicate had opened the door to the fullness of his relationships. Once again, he has been placed squarely in the room and into the nexus of his family, including his daughter Tamika. ${ }^{122}$

\section{A Right to Consciousness}

Even when I was a medical student there was not much that could be done for patients so gravely injured. We would brush them off with a, "So, what?" But now there is the emergence of a "so," so we must ask ourselves what we are going to do, both diagnostically and therapeutically.

This is more than an insurance issue, though it surely is that as well. We must affirm the recognition and engagement of consciousness as a civil right, ${ }^{123,124}$ as a right that is fundamental and neither discretionary nor a mere entitlement. Instead, we must realize that it is an ethical imperative to view consciousness, when it is present, as a civil right. ${ }^{125}$

This is the civil rights agenda for our generation. We must embrace those who have too long been cast aside. We must acknowledge that patients who are minimally conscious must be properly diagnosed, because it is simply wrong to segregate brain-injured but conscious people from those who know them and love them by keeping them in chronic care facilities far from their homes and without diagnostic accuracy. And it is equally wrong to deprive them access to proper rehabilitation, emerging drugs, or neuroprosthetic interventions that might foster their recoveries or ability to engage with others. ${ }^{126}$

To perpetuate patterns of neurosegregation-and I use that word with grave intent-that is, to segregate these people, given what we now know about the potential of the minimally conscious patient, is simply unethical. It is unethical because it is cruel to deprive a conscious individual the opportunity to experience 
human companionship and community. That possibility is extinguished when consciousness - that spark of personhood on which our collective relationships hinge-is overlooked or ignored. When that happens, consciousness might as well be extinguished.

Whether it is snuffed out through an error of omission or willful neglect, the failure to properly diagnose consciousness or sustain its emergence is not an option but a moral obligation. It is a responsibility that makes engagement possible. For with a failure to identify a person as conscious there is no reason to try and communicate. And with that omission comes a failure to engage and continued exile from the human community, which is marked by shared communication. Just consider the following thought experiment: imagine yourself in the bed, mistaken as unconscious when you are not, perhaps barely recognizing the maternal gaze directed toward you, as you are unable to convey evidence of your presence. Simply stated, without being properly identified as conscious, these patients will not be as fully integrated into society as might be possible. Instead, they will continue to be segregated and set apart from others with whom they might have been able to relate.

The importance of such integration is a point stressed by the $2006 \mathrm{UN}$ Convention on the Rights of the Disabled. That venerable document clearly states that persons with disabilities should "have access to . . . support services ... necessary to support living and inclusion in the community, and to prevent isolation or segregation from the community." 127 We can no longer view the medical needs of persons with disabilities-especially any technological advances that might restore their ability to be reintegrated into society through the provision of voice and the ability to make contact and communicate with others-as discretionary; rather, we must see them as compelling. Here the holy grail, the realization of the UN Convention and the Americans with Disability Act, ${ }^{128}$ is reintegration through the restoration of functional communication. With it comes the ability to rejoin the community.

\section{Technologies and Capabilities}

Inviolable access to neuroprosthetic technology, and enabling medical care and rehabilitation, can also be asserted through a capabilities argument, a discourse that in some respects has superseded more traditional appeals to human rights. The capabilities approach was advanced by Chicago's Martha Nussbaum ${ }^{129}$ and the economist and Nobel Laureate Amartya Sen, ${ }^{130,131}$ who wrote of the limitations of negative rights if their achievement did not sufficiently result in justice. Sen argues that something more instrumental is needed to link right to constructive action and the capability to do something, to function, to achieve a good or fulfill a need-or, in the philosopher Sridhar Venkatapuram's more recent formulation, to fulfill a goal. ${ }^{132}$

Access to neuroprosthetics has an essential moral quality because it establishes an inherent human right or, better yet, fosters capability-the capability to use communication to form and be part of the human community. Guaranteeing access to neuroprosthetics, drugs, devices and rehabilitation allows us to embrace the dispossessed so that once again they might enjoy the warmth and solidarity of human companionship, experiences grounded, in large part, on the restoration of voice and functional communication. 


\section{Giving Voice to Consciousness}

In short, this issue becomes an argument in favor of integration over segregation. ${ }^{133}$ If individuals who might be able to communicate are denied the resources to do so, they are then denied access to being maximally integrated into society. This makes you, the neuroscience community, indispensable.

These people, our fellow citizens, cannot do this without your talents and hard work. This is as much a scientific challenge as a moral calling. And I hope you will do all you can to make a difference that makes a difference.

Here are three things that should be at the top of our agenda of inclusion: First, we need to establish medical parity and basic levels of medical care for patients with disorders of consciousness, with ongoing clinical evaluation that reflects their progression from injury to recovery. This starts with the establishment of an ICD code for the minimally conscious state. This includes neuropalliative care, pain and symptom management, for patients who can't tell you they are in pain or emotional distress. Second, we need more science to better understand cognitive motor dissociation and how to overcome it with neuroprosthetics, drugs, and rehabilitation. Finally, we need to ensure that people in a minimally conscious state are fully enfranchised under the Americans with Disabilities Act so they can gain the protection of the law.

\section{In Memoriam}

This agenda comes too late for Maggie, who died on August 2, 2015, at the age of 31. She did not benefit from this agenda, but she had a loving mother who was her devoted advocate. Maggie and Nancy created a new life together. Among their new joys was painting in tandem. A depiction of a sunflower that they painted together adorned the program at Maggie's memorial on August 29. This lecture is dedicated to her memory.

\section{Notes}

1. Fins JJ. Rights Come to Mind: Brain Injury, Ethics and the Struggle for Consciousness. New York: Cambridge University Press; 2015.

2. Speak Your Mind Foundation. Video of Maggie Worthen using neuroprosthesis. Courtesy of Schiff ND, Bacher D; 2013 Aug. http://speakyourmindfoundation.org (last accessed 3 Jun 2016).

3. See note 1, Fins 2015.

4. Schiff ND. Cognitive motor dissociation following severe brain injuries. Journal of the American Medical Association Neurology 2015 Oct 19;1-3. doi:10.1001/jamaneurol.2015.2899. [Epub ahead of print.]

5. See note 1, Fins 2015.

6. Fins JJ. Disorders of consciousness and disordered care: Families, caregivers and narratives of necessity. Archives of Physical Medicine and Rehabilitation 2013;94(10):1934-9.

7. Giacino JT, Fins JJ, Laureys S, Schiff ND. Disorders of consciousness after acquired brain injury: The state of the science. Nature Reviews Neurology 2014;10:99-114.

8. See note 1, Fins 2015.

9. See note 1, Fins 2015.

10. Fins JJ. Minds apart: Severe brain injury. In: Freeman M, ed. Law and Neuroscience, Current Legal Issues. Vol. 13. Oxford: Oxford University Press; 2010:367-84.

11. Fins JJ. A Palliative Ethic of Care: Clinical Wisdom at Life's End. Sudbury, MA: Jones and Bartlett; 2006.

12. Matter of Karen Quinlan, 70 N.J. 10, 355 A.2d 677 (1976).

13. Jennett B, Plum F. Persistent vegetative state after brain damage: A syndrome in search of a name. Lancet 1972;1(7753):734-7. 
14. Jennett B, Teasdale G, Braakman R, Minderhoud J, Knill-Jones R. Predicting outcome in individual patients after severe head injury. Lancet 1976;1(7968):1031-4.

15. Reis DJ, Posner JB, eds. Frontiers of Neuroscience, a Symposium in Honor of Fred Plum. New York: New York Academy of Sciences; 1994.

16. See note 13, Jennett, Plum 1972.

17. Jennett B. The Vegetative State. New York: Cambridge University Press; 2002.

18. See note 11, Fins 2006.

19. See note 12, Matter of Karen Quinlan.

20. Fins JJ. Constructing an ethical stereotaxy for severe brain injury: Balancing risks, benefits and access. Nature Reviews Neuroscience 2003;4:323-7.

21. See note 11, Fins 2006.

22. See note 11, Fins 2006.

23. Kinney HC, Korein J, Panigrahy A, Dikkes P, Goode R. Neuropathological findings in the brain of Karen Ann Quinlan - the role of the thalamus in the persistent vegetative state. New England Journal of Medicine 1994;330:1469-75.

24. See note 20, Fins 2003.

25. Center for Practical Bioethics. Ethical Considerations in Diagnosing Disorders of Consciousness MP3. Podcast with Joseph J. Fins, M.D., F.A.C.P. and Arthur Caplan, Ph.D. on "Cruzan Twenty Years Later and Disorders of Consciousness."Central for Practical Ethics. Available at http: / / practicalbioethics.org/component/k2/item/156-ethical-considerations-in-diagnosing-disordersof-consciousness (recorded 6 Dec 2010;m last accessed 8 Jun 2016).

26. McCloskey EL. Bioethics inside the Beltway/the Patient Self-Determination Act. Kennedy Institute of Ethics Journal 1991 June:163-9.

27. Wolf SM, Boyle P, Callahan D, Fins JJ, Jennings B, Lindemann Nelson J, et al. Sources of concern about the Patient Self-Determination Act. New England Journal of Medicine 1991;325:1666-71.

28. See note 1, Fins 2015.

29. See note 11, Fins 2006.

30. Fins JJ, Plum F. Neurological diagnosis is more than a state of mind: Diagnostic clarity and impaired consciousness. Archives of Neurology 2004;61(9):1354-5.

31. Fins JJ, Schiff ND. The after-life of Terri Schiavo. The Hastings Center Report 2005;35(4):8.

32. Fins JJ. Affirming the right to care, preserving the right to die: Disorders of consciousness and neuroethics after Schiavo. Supportive \& Palliative Care 2006;4(2):169-78.

33. Cover. U.S. News and World Report 2005 Apr 4.

34. See note 32, Fins 2006.

35. Fins JJ. Rethinking disorders of consciousness: New research and its implications. The Hastings Center Report 2005;35(2):22-4.

36. Schiff ND, Fins JJ. Hope for "comatose" patients. Cerebrum 2003;5(4):7-24. Reprinted as Schiff ND, Fins JJ. Hope for "comatose" patients: "A cerebrum classic." In: Read CA, ed. The Dana Foundation's Cerebrum 2007. New York: Dana Press; 2007:185-203.

37. Fins JJ, Master MG, Gerber LM, Giacino JT. The minimally conscious state: A diagnosis in search of an epidemiology. Archives of Neurology 2007;64(10):1400-5.

38. Giacino JT, Ashwal S, Childs N, Cranford R, Jennett B, Katz DI, et al. The minimally conscious state: Definition and diagnostic criteria. Neurology 2002;58(3):349-53.

39. See note 1, Fins 2015.

40. Fins JJ, Hersh J. Solitary advocates: The severely brain injured and their surrogates. In: Hoffman B, Tomes N, Schlessinger M, Grob R, eds. Transforming Health Care from Below: Patients as Actors in U.S. Health Policy. New Bunswick, N.J.: Rutgers University Press; 2011.

41. Fins JJ. A leg to stand on: Sir William Osler and Wilder Penfield's "Neuroethics." American Journal of Bioethics 2008;8(1):37-46.

42. Penfield W. The Significance of the Montreal Neurological Institute. In Neurological Biographies and Addresses. Ed. Milford H. Foundation Volume. London: Oxford University Press; 1936, at 42-43.

43. Fins JJ. Lessons from the injured brain: A bioethicist in the vineyards of neuroscience. Cambridge Quarterly of Healthcare Ethics 2009;18(1):7-13.

44. See note 43, Fins 2009.

45. See note 36, Schiff, Fins 2003.

46. Addley E. Terry talks. Guardian 2013 July 11; available at http:/ /www.theguardian.com/society/ 2003/jul/11/health.lifeandhealth (last accessed 30 Oct 2015).

47. See note 1, Fins 2015. 


\section{Giving Voice to Consciousness}

48. See note 1, Fins 2015.

49. See note 1, Fins 2015.

50. See note 1, Fins 2015.

51. See note 38, Giacino et al. 2002.

52. Voss HU, Uluc AM, Dyke JP, Watts R, Kobylarz EJ, McCandliss BD, et al. Possible axonal regrowth in late recovery from minimally conscious state. Journal of Clinical Investigation 2006;116:2005-11.

53. Mukherjee P, McKinstry RC. Diffusion tensor imaging and tractography of human brain development. Neuroimaging Clinics of North America 2006;16(1):19-43.

54. See note 1, Fins 2015.

55. Laureys S, Faymonville ME, Peigneux P, Damas P, Lambermont B, Del Fiore G, et al. Cortical processing of noxious somatosensory stimuli in the persistent vegetative state. Neuroimage 2002;17(2):732-41.

56. Schiff ND, Rodriguez-Moreno D, Kamal A, Kim K, Giacino J, Plum F, et al. fMRI reveals large scale network activation in minimally conscious patients. Neurology 2005;64:514-23.

57. See note 1, Fins 2015.

58. Carey B. New signs of awareness in some brain-injured patients. New York Times 2005 Feb 8:A-1.

59. Owen AM, Coleman MR, Boly M, Davis MH, Laureys S, Pickard JD: Detecting awareness in the vegetative state. Science 2006;313(5792):1402.

60. Fins JJ, Schiff ND. Shades of gray: New insights from the vegetative state. The Hastings Center Report 2006;36(6):8.

61. Monti MM, Vanhaudenhuyse A, Coleman MR, Boly M, Pickard JD, Tshibanda L, et al. Willful modulation of brain activity in disorders of consciousness. New England Journal of Medicine 2010; 362(7):579-89.

62. Giacino JT, Kalmar K, Whyte J. The JFK coma recovery scale-revised: Measurement characteristics and diagnostic utility. Archives of Physical Medicine and Rehabilitation 2004;85(22):2020-2029.

63. Bardin JC, Fins JJ, Katz DI, Hersh J, Heier LA, Tabelow K, et al. Dissociations between behavioural and functional magnetic resonance imaging-based evaluations of cognitive function. Brain 2011;134(3):769-82.

64. See note 1, Fins 2015, at 257.

65. See note 6, Fins 2013.

66. Fins JJ. Neuroethics and neuroimaging: Moving towards transparency. American Journal of Bioethics 2008;8(9):46-52.

67. See note 63, Bardin et al. 2011.

68. See note 1, Fins 2015.

69. See note 40, Fins, Hersh 2011.

70. See note 1, Fins 2015.

71. Fins JJ. Severe brain injury and organ donation: A call for temperance. AMA Virtual Mentor 2012;14(3):221-6; available at http://virtualmentor.ama-assn.org/2012/03/stas1-1203.html (last accessed 3 Jun 2016).

72. See note 1 , Fins 2015, at 55.

73. See note 66, Fins 2008.

74. Schnakers C, Vanhaudenhuyse A, Giacino J, Ventura M, Boly M, Majerus S, et al. Diagnostic accuracy of the vegetative and minimally conscious state: Clinical consensus versus standardized neurobehavioral assessment. BioMedCentral Neurology 2009;9:35.

75. See note 62, Giacino et al. 2004.

76. Fins JJ. The ethics of measuring and modulating consciousness: The imperative of minding time. Progress in Brain Research 2009;177C:371-82.

77. Taylor CM, Aird VH, Tate RL, Lammi MH. Sequence of recovery during the course of emergence from the minimally conscious state. Archives of Physical Medicine and Rehabilitation 2007;88(4): 521-5.

78. Blake R. The Day Donny Herbert Woke Up. New York: Harmony Books; 2007.

79. See note 78 , Blake 2007.

80. Fins JJ. A review of, The Day Donny Herbert Woke Up by Rich Blake. New York: Harmony Books, 2007. JAMA 2008;299(8):959-60.

81. See note 80, Fins 2008.

82. See note 78, Blake 2007.

83. See note 1, Fins 2015.

84. See note 6, Fins 2013. 
85. Fins JJ. "Wait, wait-don't tell me"... tuning in the injured brain. Archives of Neurology 2012; 69(2):158-60.

86. See note 6, Fins 2013.

87. Gladieux JE, Basile M. Jimmo and the improvement standard: Implementing Medicare coverage through regulations, policy manuals and other guidance. American Journal of Law and Medicine 2014;40(1):7-25.

88. Fins JJ, Wright MS, Kraft C, Rogers A, Romani MB, Goodwin S, et al. Whither the "improvement standard"? Coverage for severe brain injury after Jimmo v. Sebelius. Journal Law Medicine and Ethics; 2016;44(1):182-193.

89. See note 1, Fins 2015.

90. See note 85, Fins 2012.

91. See note 76, Fins 2009.

92. Fins JJ, Schiff ND, Foley KM. Late recovery from the minimally conscious state: Ethical and policy implications. Neurology 2007;68:304-7.

93. Schiff ND, Giacino J, Kalmar K, Kobylarz E, Baker K, Farris S, et al. Partial restoration of behavioral responsiveness and arousal regulation by electrical stimulation of the human intralaminar thalamic nuclei. Society for Neuroscience 36th Annual Meeting; 2006 Oct. Abstract.

94. Schiff ND, Giacino JT, Kalmar K, Victor JD, Baker K, Gerber M, et al. Behavioral improvements with thalamic stimulation after severe traumatic brain injury. Nature 2007;448(7153):600-3.

95. Schiff ND, Fins JJ. Deep brain stimulation and cognition: Moving from animal to patient. Current Opinion in Neurology 2007;20(6):638-42.

96. See note 1, Fins 2015.

97. Fins JJ. A proposed ethical framework for interventional cognitive neuroscience: A consideration of deep brain stimulation in impaired consciousness. Neurological Research 2000;22:273-8.

98. Fins JJ. From psychosurgery to neuromodulation and palliation: History's lessons for the ethical conduct and regulation of neuropsychiatric research. Neurosurgery Clinics of North America 2003; 14(2):303-19.

99. Fins JJ, Giacino J, Rezai A, Schiff N. Ethical insights from a neuromodulation trial to restore function in the minimally conscious state. Society for Neuroscience 36th Annual Meeting; 2006 Oct. Abstract.

100. Schiff ND, Giacino JT, Fins JJ. Deep brain stimulation, neuroethics and the minimally conscious state: Moving beyond proof of principle. Archives of Neurology 2009;66(6):697-702.

101. Fins JJ. Deep brain stimulation, deontology and duty: The moral obligation of non-abandonment at the neural interface. Journal of Neural Engineering 2009;6(5):50201. Epub 2009 Sept 1.

102. Fins JJ. Deep brain stimulation: Ethical issues in clinical practice and neurosurgical research. In: Krames E, Peckham PH, Rezai A, eds. Neuromodulation. London: Elsevier; 2009:81-91.

103. Fins JJ, Schiff ND. Conflicts of interest in deep brain stimulation research and the ethics of transparency. Journal of Clinical Ethics 2010;21(2):125-32.

104. Fins JJ, Schlaepfer TE, Nuttin B, Kubu CS, Galert T, Sturm V, et al. Ethical guidance for the management of conflicts of interest for researchers, engineers and clinicians engaged in the development of therapeutic deep brain stimulation. Journal of Neural Engineering 2011;8(3):033001. doi:10.1088/1741-2560/8/3/03301. [Epub ahead of print.]

105. Giacino J, Fins JJ, Machado A, Schiff ND. Central thalamic deep brain stimulation to promote recovery from chronic post-traumatic minimally conscious state: Challenges and opportunities. Neuromodulation 2012;15(4):330-49.

106. See note 1, Fins 2015.

107. Fins JJ. Justice, clinical research and the minimally conscious state. The President's Bioethics Commission. (By invitation.) New York; 2011 May 18.

108. See note 100, Schiff et al. 2009.

109. See note 94 , Schiff et al. 2007.

110. See note 1, Fins 2015.

111. See note 94 , Schiff et al. 2007.

112. See note 94 , Schiff et al. 2007.

113. See note 94 , Schiff et al. 2007.

114. Thomas L. The Lives of a Cell: Notes of a Biology Watcher. New York: The Viking Press; 1974, at 33.

115. See note 1, Fins 2015.

116. See note 100, Schiff et al. 2009.

117. See note 1, Fins 2015. 


\section{Giving Voice to Consciousness}

118. Gillet G. Minimally conscious state, deep brain stimulation and what is worse than futility. Journal of Bioethical Inquiry 2011;8(2):145-9.

119. See note 97, Fins 2000.

120. See note 1, Fins 2015.

121. See note 1 , Fins 2015 , at $243-7$

122. See note 1 , Fins 2015 , at $243-7$.

123. See note 10, Fins 2010.

124. See note 1, Fins 2015.

125. See note 1, Fins 2015.

126. See note 1, Fins 2015.

127. United Nations Convention on the Rights of Persons with Disability. Geneva: United Nations; 2006.

128. Americans with Disabilities Act of 1990, Pub. L. No. 101-336, 104 Stat. 328 (1990).

129. Nussbaum M. Capabilities as fundamental entitlements: Sen and social justice. Feminist Economics 2003;9(2-3):33-59.

130. Sen A. Commodities and Capabilities. New York: Oxford University Press; 1999.

131. Sen A. Well-being, agency and freedom: The Dewey lectures 1984. Journal of Philosophy 1985; 82(4):169-221.

132. Venkatapuram S. Health Justice: An Argument from the Capabilities Approach. Cambridge: Polity Press; 2011.

133. See note 1, Fins 2015. 